\title{
Diurnal variation of tropospheric temperature at a tropical station
}

\author{
K. Revathy ${ }^{1}$, S. R. Prabhakaran Nayar ${ }^{2}$, and B. V. Krishna Murthy ${ }^{2}$ \\ ${ }^{1}$ Department of Computer Science, University of Kerala, Kariavattom, Trivandrum 695581, India \\ ${ }^{2}$ Department of Physics, University of Kerala, Kariavattom, Trivandrum 695581, India
}

Received: 9 October 2000 - Revised: 6 July 2001 - Accepted: 6 July 2001

\begin{abstract}
The vertical velocity in the troposphere-lower stratosphere region measured using MST radar has been utilized to evaluate the temperature profile in the region. The diurnal variation of the tropospheric temperature on one day in August 1998 at the tropical station Gadanki $\left(13.5^{\circ} \mathrm{N}\right.$, $79.2^{\circ} \mathrm{E}$ ) has been studied using the MST radar technique. The diurnal variation of the temperature revealed a prominent diurnal variation with the peak in the afternoon hours increasingly delayed in altitude. The tropopause temperature and altitude exhibited a clear diurnal cycle.
\end{abstract}

Key words. Atmospheric composition and structure (pressure, density and temperature; troposphere - composition and chemistry; instruments and technique)

\section{Introduction}

The MST radar operating in a VHF band is a very powerful tool to explore the atmospheric dynamics of the lower and middle atmosphere. It has the capability of measuring the wind in the troposphere and the lower stratosphere with time scales of a few tens of seconds. These measurements provide a powerful means of determining the spectra of short period fluctuations in the atmosphere and the Brunt-Vaisala frequency. The possibility of the derivation of temperature profile from the MST radar observation of vertical wind has been pointed out by Röttger (1986). Following this, Revathy et al. (1996) have developed a method for determining tropospheric and lower stratosheric temperature from the MST radar observations of vertical wind with good altitude and temporal resolution. The knowledge of atmospheric temperature variation with altitude is very important in the study of atmospheric turbulence and atmospheric stability. In this work, we have utilized the MST radar observations of vertical wind fluctuation to evaluate the temperature profile of the troposphere and lower stratosphere region. By evaluating the temperature profiles at regular intervals of time, the diurnal

Correspondence to: K. Revathy (srp@md2.vsnl.net.in) variation of temperature in the troposphere and stratosphere and the features of the tropopause are also evaluated.

\section{Measurement of vertical velocity using MST radar}

The Mesosphere Stratosphere Troposphere (MST) radar at Gadanki $\left(13.5^{\circ} \mathrm{N}, 79.2^{\circ} \mathrm{E}\right)$ is a highly sensitive, pulse coded VHF phased array at $53 \mathrm{MHz}$ and with an average power aperture product of $5 \times 10^{7} \mathrm{Wm}^{2}$ and altitude resolution of $150 \mathrm{~m}$ in the vertical direction. The radar system details are given in Rao et al. (1995). The radar provides the backscattered signals in the vertical direction in the altitude range 3.75 to $30 \mathrm{~km}$ with good SNR. The data from the I and Q channels of the MST radar are usually coherently integrated for many pulses. The inter-pulse period and the coherent integration will limit the bandwidth of the observation window. The time series of data from I and Q channels are subjected to an FFT analysis and the Doppler spectra are obtained at regular intervals. From the spectrum output, the spectral moments are evaluated. The first moment provides the mean Doppler frequency from which vertical wind velocity can be evaluated. Thus a time series of vertical wind velocity sampled at 46 seconds is obtained in the altitude range of $3.75 \mathrm{~km}$ to $30.6 \mathrm{~km}$ at intervals of $150 \mathrm{~m}$. These time series are subjected to FFT to obtain the spectra and from these spectra, the spectral peak corresponding to the B-V frequency is identified. This B-V frequency which gives the gradient of the temperature is used to derive the temperature profile. Typical sample spectra of vertical velocity at an altitude of $5.1 \mathrm{~km}$ using the vertical velocity data sampled at a $46 \mathrm{~s}$ interval during 2:55 LT to 21:56 LT on 24 August 1998 is shown in Fig. 1.

In order to investigate the diurnal variation of tropospheric temperature, the spectral data is collected on every alternate hour during 24-25 August 1998, thus providing twelve sets of data samples which enabled us to study the diurnal evolution of the temperature profiles. In the diurnal cycles, the radar is operated in the temperature mode, i.e. in a single beam mode by continuously observing the vertical wind for 


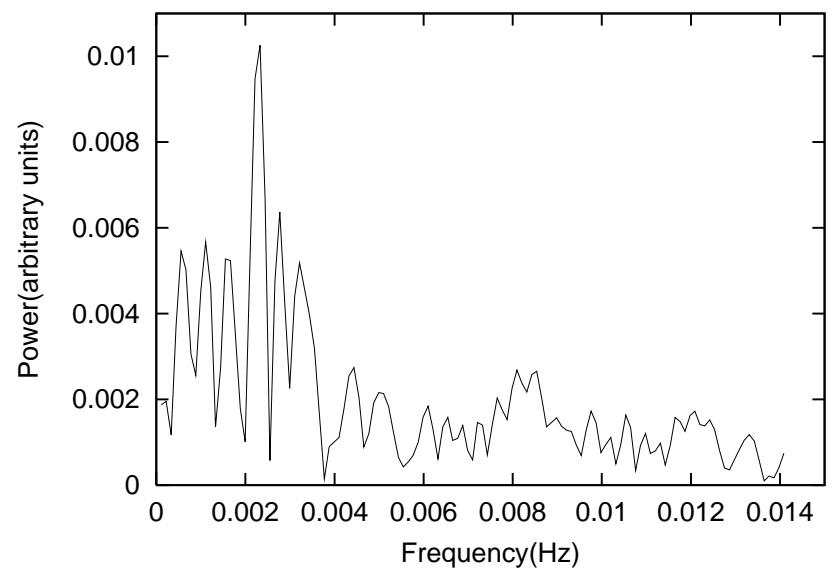

Fig. 1. Typical vertical velocity spectrum at an altitude of $5.1 \mathrm{~km}$ during 20:55 to 21:56 LT on 24 August 1998.

about one hour. Under this scheme, the vertical wind data is available at a 46 second interval with about 80 cycles of vertical beam observation which is sufficient for the evaluation of the vertical wind temporal spectrum. This observation is preceded and followed by the operation of the MST radar in the five beam mode to evaluate the background wind in order to obtaining an impression of the atmospheric conditions.

\section{Evaluation of temperature}

The spectra of vertical wind velocity depicted in Fig. 1 show a typical pattern with a peak at the Brunt-Vaisala frequency (Röttger, 1986; Scheffler and Liu, 1985), a steep decrease in amplitude in the high frequency side, and a fairly shallow decrease in amplitude in the low frequency side. Based on earlier studies by Röttger (1986), Revathy et al. (1996) developed a method for determining tropospheric and lower stratospheric temperature from MST radar observations of vertical wind. In this method, using vertical wind velocity data (w) sampled at 46 second intervals for a duration of one hour, the temporal spectrum of $\mathrm{w}$ is obtained. From the spectrum, the Brunt-Vaisala $(\mathrm{B}-\mathrm{V})$ frequency $(\mathrm{N})$ is determined by identifying the spectral peak corresponding to $\mathrm{N}$ based on the following criteria:

1. The spectral peak at the B-V frequency is the highest and most prominent;

2. The spectrum on the high frequency side of the B-V frequency spectral peak shows a steep decrease with no prominent spectral peaks.

Four typical profiles of angular Brunt-Vaisala frequency $\left(\omega_{N}\right)$ are shown in Fig. 2.

The $\mathrm{B}-\mathrm{V}$ frequency $\mathrm{N}(\mathrm{h})$ at altitude $\mathrm{h}$ is related to the temperature $\mathrm{T}(\mathrm{h})$ by

$N(h)^{2}=\frac{g}{T(h)}\left[\frac{\partial T(h)}{\partial h}+\Gamma\right]$
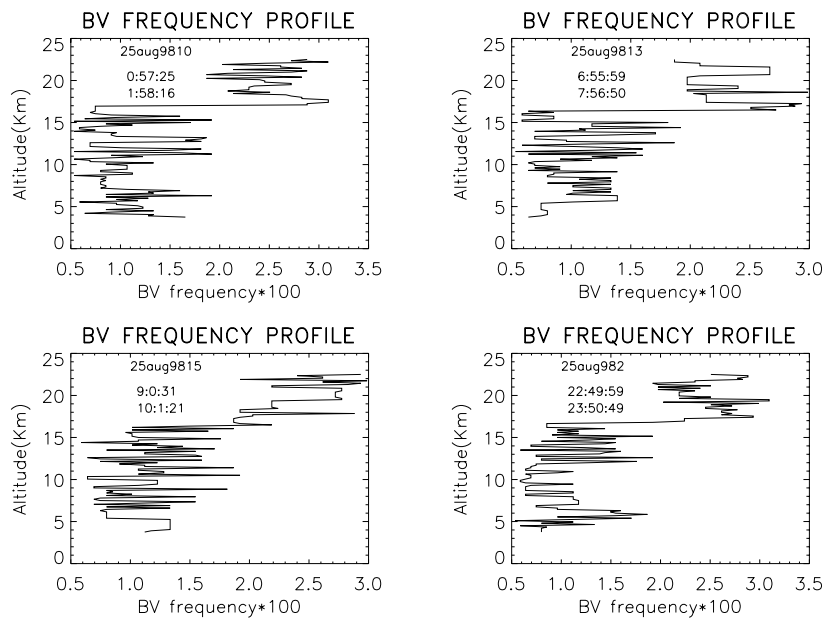

Fig. 2. Altitude variation of $\omega_{N}$ in the troposphere-stratosphere region on 25 August 1998 during the time intervals (a) 00:57 to 01:58 (b) 06:55 to 07:56 (c) 09:00 to $10: 01$ and (d) $22: 49$ to $23: 50$ on 24 August 1998.

or

$\frac{\partial T(h)}{\partial h}=\left[\frac{N(h)^{2} T(h)}{g}-\Gamma\right]$

where $\mathrm{g}$ is the acceleration due to gravity, $\mathrm{h}$ is the altitude and $\mathrm{T}$ is the adiabatic lapse rate (dry). Equation (2) is integrated to obtain $\mathrm{T}(\mathrm{h})$ from $\mathrm{N}(\mathrm{h})$ which is determined from the temporal spectra of vertical wind at different altitudes with boundary value $T_{o}$ at $h_{o}$ (the lowest altitude at which $\mathrm{N}$ is obtained). $T_{o}$ is obtained from the ground temperature value and the iterative method described in Revathy et al. (1996). From the measured ground temperature, the temperature at $3.75 \mathrm{~km}$ is obtained assuming a lapse rate of $6 \mathrm{~K} / \mathrm{km}$ which is an average value of the lapse rate in the lower troposphere that is applicable for the Indian tropical region (Sasi, 1984). This value of temperature at $3.75 \mathrm{~km}$ is used as a reference temperature in Eq. (2) to derive the temperature profile, from which the lapse rate in the altitude range of $3.75 \mathrm{~km}$ to $5 \mathrm{~km}$ is obtained and used to calculate the temperature at 3.75 from the ground value. This new reference value of temperature is used in Eq. (2) to derive one more the temperature profile.

The limitations of this method have been discussed in detail in Revathy et al. (1997). It is basically applicable under convectively stable conditions and when the wind and wind shear are not very high. The horizontal wind introduces a Doppler shift to the gravity waves. However, as we do not know the phase and speed of the gravity wave, we cannot estimate the Doppler shift. The effect of this Doppler shift is to render the temporal spectrum of the vertical wind (from which the BV frequency is obtained) broaden around the BV frequency for a short period gravity wave. This makes the estimate of the BV frequency difficult. But in our analysis high horizontal winds $(20 \mathrm{~m} / \mathrm{s})$ are not encountered and so the effect would be insignificant. Since we could estimate the BV frequency in almost all cases, convective instability was 

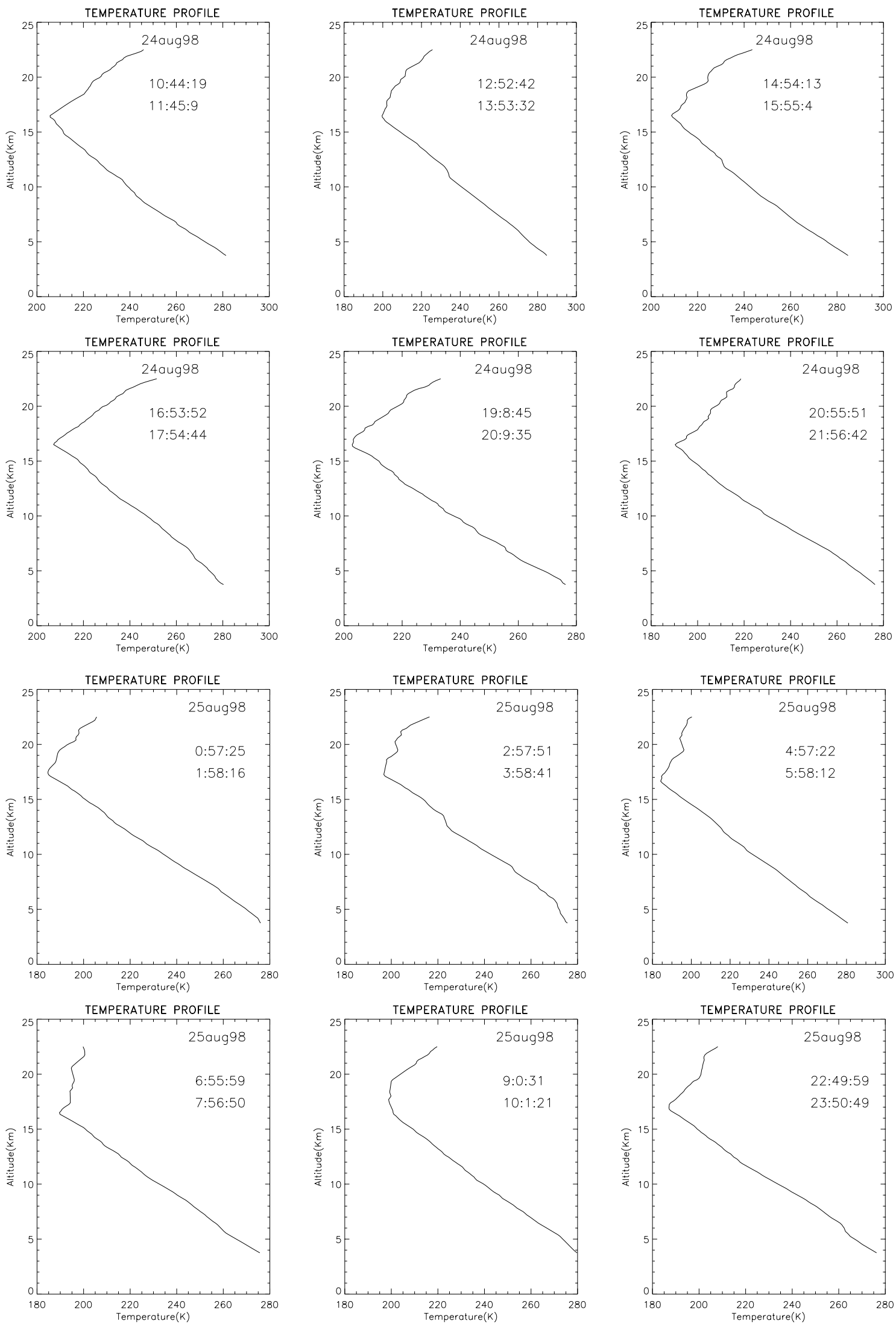

Fig. 3. Twelve vertical profiles of temperature during 10:44 LT on 24 August to 10:01 on 25 August 1998 at regular two hours intervals. 


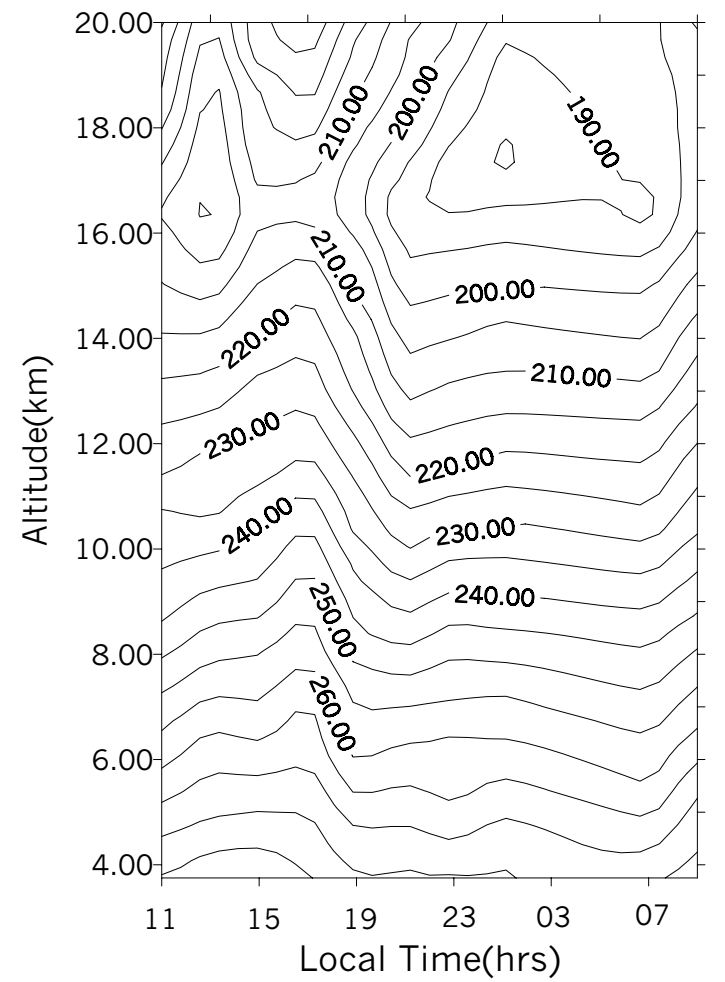

Fig. 4. Diurnal evolution of the vertical profile of temperature during 24-25 August 1998.

not encountered. Only convectively stable conditions prevailed and the $\mathrm{BV}$ frequency itself is a measure of convective stability. The MST radar is operated with the antenna beam pointing in the vertical direction in order to obtain the vertical wind velocity at intervals of $46 \mathrm{~s}$ for a duration of 60 minutes. Such 60 minute observations are carried out 12 times on 2425 August 1998 at roughly 2 hour intervals. Each such observation is preceded by 10 minutes of radar operation with 5 beams to determine the background wind profile. It is observed that the horizontal wind is quite low, not exceeding $20 \mathrm{~m} / \mathrm{s}$ on the day of observation. Each 60 minute data of vertical wind from the above observation is subjected to an FFT analysis to obtain the Brunt-Vaisala frequency profiles (Fig. 2) and hence, temperature profiles as described above. The errors involved in the determination of temperature have been studied by Revathy et al. (1998). The twelve profiles of atmospheric temperature at the troposphere-stratosphere region from 10:37:10 LT, 24 August to 10:07:35 LT, 25 August 1998 at intervals of roughly 2 hours are depicted in Fig. 3 in the $3.75 \mathrm{~km}$ to $25 \mathrm{~km}$ altitude region.

\section{Diurnal variation of the vertical profiles of tempera- ture during 24-25 August 1998}

The profiles are modulated by fluctuations which are more prominent in the lower stratosphere than in the troposphere. The tropopause level appears to be clearly defined in almost
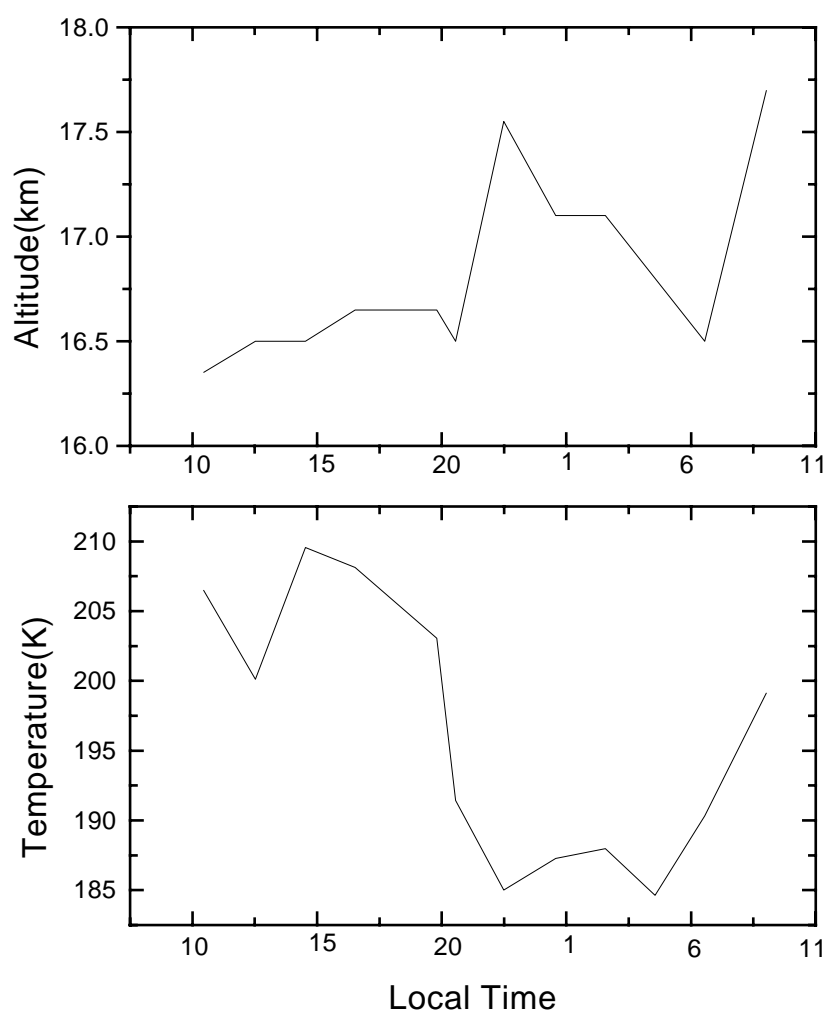

Fig. 5. Temporal variation of tropopause altitude and temperature during 11:00 LT on 24 August to 10:00 LT on 25 August 1998.

all the profiles with a sharp minimum in temperature. To study the diurnal variation of temperature at each height, the temperature data is exhibited as contours in Fig. 4. It is seen that the temperature below $\sim 16 \mathrm{~km}$ (troposphere) exhibits a prominent peak, around 16 hours. The peak is quite broad and appears to be delayed with increasing height. It is wellknown that the surface temperature is a maximum at around 14 hours due to the solar heating diurnal cycle (especially in the tropics). How the diurnal variation of the heating of the surface and the troposphere can affect this observed diurnal temperature variation needs to be subsequently investigated.

With the aim of seeing the diurnal variation of the tropopause temperature and height, the tropopause height is determined for each profile as the height of minimum temperature. The tropopause temperature and heights obtained are shown in Fig. 5. The tropopause temperature reveals a prominent diurnal cycle with broad maximum and minimum at 15:00 and 01:00, respectively. The tropopause height, in general, shows variation opposite to that of the tropopause temperature. The tropopause (temperature) diurnal cycle appears to respond directly to surface heating (solar insolation), as hypothesized by Reid and Gage (1981).

\section{Conclusion}

The study of the diurnal cycle of tropospheric temperature revealed the following: 
1. Tropospheric temperatures exhibit a prominent diurnal variation with one peak occurring at 16:00 LT. The observed diurnal cycle appears to be driven by surface heating caused by solar insolation;

2. The occurrence of the afternoon peak is increasingly delayed with height;

3. The tropopause temperature exhibits a prominent diurnal cycle with a peak around 15:00 and appears to respond to surface heating.

Acknowledgement. This work was carried out with the financial support from Department of Science and Technology, Government of India.

Topical Editor J.-P. Duvel thanks J. Röttger for his help in evaluating this paper.

\section{References}

Rao, P. B., Jain, A. R., Kishore, P., Balamuralidhar, P., Damle, S. H., and Viswanathan, G., Indian MST radar 1. System description and sample vector wind measurements in ST mode, Radio
Science, 30, 1125-1138, 1995.

Reid, G. C. and Gage, K. S., On the annual variation in height of the tropical tropopause, J. Atmos. Sci., 38, 1928-1938, 1981.

Revathy, K., Prabhakaran Nayar, S. R., and Krishnamurthy, B. V., Deduction of temperature profile from MST radar observation of vertical wind, Geophys. Res. Letters, 19, 326-342, 1996.

Revathy, K., Prabhakaran Nayar, S. R., and Krishnamurthy, B. V., Troposphere and lower stratosphere temperature profile and its evolution from MST radar observations, STEP Handbook, Ed.: Belva Edwards, Illinois, USA, 180-183, 1997.

Revathy, K., Prabhakaran Nayar, S. R., and Krishnamurthy, B. V., Estimation of error in the determination of temperature using MST radar, Geophys. Res. Letters, 19, 326-342, 1996, Indian J. Radio and Space Sci., 27, 150-154, 1998.

Röttger, J., Determination of Brunt-Vaisala frequency from vertical velocity spectra, MAP Handbook, 20, 299-312, 1986.

Sasi, M. N., A reference atmosphere for the Indian equatorial zone, Indian J. Radio and Space Sci., 23, 150-154, 1994.

Scheffler, A. O. and Liu, C. H., On observation of gravity wave spectra in the atmosphere by using MST radars, Radio Sci., 20, 1309-1322, 1985

Scheffler, A. O. and Liu, C.H., The effects of Doppler shift on gravity wave spectra observed by MST radar, J. Atmos. Terr. Phys, 48, 1125-1231, 1986. 